\title{
Incidence of overweight and obesity in a Mediterranean population-based cohort: The Cornellà Health Interview Survey Follow-up Study (CHIS.FU)
}

\author{
Rocío Ortiz-Moncada a,*, Montse García b, Laura I. González-Zapata c, \\ Esteve Fernandez ${ }^{\mathrm{b}, \mathrm{e}}$, Carlos Álvarez-Dardet ${ }^{\mathrm{a}, \mathrm{d}}$ \\ a Public Policy and Health Observatory, Area of Preventive Medicine and Public Health, University of Alicante, Alicante, Spain \\ b Cancer Prevention and Control Unit, Catalan Oncology Institute, L'Hospitalet de Llobregat, Barcelona, Spain \\ c School of Nutrition and Dietetics School-University of Antioquia, Medellín, Colombia \\ d CIBER en Epidemiología y Salud Pública (CIBERESP), University of Alicante, Alicante, Spain \\ e Department of Clinical Sciences, Campus of Bellvitge, University of Barcelona, Barcelona, Spain
}

\section{A R T I C L E I N F O}

Available online $\mathrm{xxxx}$

\section{Keywords:}

Overweight

Obesity

Population

Male

Female

Cohort study

Body Mass Index

\begin{abstract}
A B S T R A C T
Objective. To study the changes in body mass index (BMI) in a population-based cohort and their relationship with sociodemographic variables in a Mediterranean-country.

Method. A prospective population-based cohort with 8-year follow-up. The data used derive from the Cornellà-Health-Interview Survey Follow-up (CHIS.FU). 1008 people aged $\geq 20$ years (females $=508$; males $=500$ ) were interviewed in 1994 and in 2002, providing self-reported weight and height data. The BMI was compared using the Wilcoxon test for paired data. Changes in the BMI were calculated and their relationship with sociodemographic-variables and lifestyles using multivariate Breslow-Cox regression.

Results. 28.1\% of participants had changed from normal-BMI in 1994 to overweight in 2002 ( women $=25.6 \%$; men $=31.6 \%$ ). $16.8 \%$ increased from overweight to obesity ( women $=25.8 \%$; men $=11.2 \%$ ). The cumulative incidence of overweight: women $=26.4 \%$; $m e n=34.0 \%$. The cumulative incidence of obesity: women $=29.9 \%$; men $=13.1 \%$. The cumulative age and sex-adjusted incidence of overweight showed a significant relationship with marital-status (married: $\mathrm{RR}=2.0 ; 95 \% \mathrm{CI}: 1.2-3.4$, divorced/ widowed: $\mathrm{RR}=4.0 ; 95 \% \mathrm{CI}: 1.7-9.3$ ) and moderate alcohol-consumption ( $\mathrm{RR}=1.86 ; 95 \% \mathrm{CI}: 1.1-3.1)$. We observed a decreased age-adjusted risk in the incidence of obesity for men ( $R R=0.49 ; 95 \% \mathrm{CI}: 0.3-0.8$ ).

Conclusion. The observed changes in the increase in the incidence of obesity and overweight indicated a similar evolution in the obesity epidemic regardless of Mediterranean dietary patterns in our population.
\end{abstract}

(c) 2009 Elsevier Inc. All rights reserved.

\section{Introduction}

The prevalence of obesity has increased in most European countries, particularly in Mediterranean and Eastern European countries (Sanz-de-Galdeano, 2005; IOTF, 2002; Haftenberger et al., 2002), and in the USA (Flegal et al., 2002). However, these data are of a cross-sectional nature or the result of trend studies which compare prevalence rates reported in surveys with independent samples over time. Prevalence data do not provide estimates on incidence nor on the causal relationship between obesity and its associated factors, thus making it difficult to target those at highest risk (Nemesure et al., 2008). More long-term follow-up is required to allow a rigorous evaluation of the temporal relations between exposure and disease risk (Mujahid et al., 2005; Williamson et al., 1991; Vasan et al., 2005). In particular, data on temporal relations, together with repeated

* Corresponding author. Area of Preventive Medicine and Public Health, Campus de Sant Vicent del Raspeig, Ap. 99, 03080 University of Alicante, Alicante, Spain. Fax: +0034965903964 .

E-mail address: rocio.ortiz@ua.es (R. Ortiz-Moncada). measures that allow the assessment of change in exposure, are important for assessing the potential impact of preventive interventions (Willett \& Colditz, 1998) and reducing the personal and public health burdens associated with excess body size.

Therefore, the aim of this study is to determine the incidence of overweight and obesity in a population-based cohort carried out on a Southern European population between 1994 and 2002, and its relationship with sociodemographic and lifestyle variables.

\section{Methods}

The Cornellà Health Interview Survey Follow-up (CHIS.FU) is a prospective cohort study of a representative sample $(n=2500: 1263$ females and 1237 males) of the non-institutionalized population (all ages) from Cornellà de Llobregat, a city located on the metropolitan area of Barcelona, Spain (Garcia et al., 2003). The cohort was established in 1994 with participants randomly selected from the general population and interviewed face-to-face in their home. In 2002, subjects were contacted and interviewed by telephone. We obtained a 64.3 percent $(n=1608)$ response from the overall cohort. Detailed information of baseline and follow-up data is available elsewhere (Garcia et al., 2003; Garcia et al., 2005a; Garcia et al., 2005b). We 
considered for the analyses, subjects aged $\geq 20$ years at baseline with complete follow-up on height and weight $(n=1.008,508$ females and 500 males). The baseline characteristics of participants at starting of follow-up $(n=1897)$ and end of follow-up $(n=1008)$ are available in a supplementary table on-line. The body mass index (BMI) was calculated as the individual's body weight divided by the square of their height and standard categories associated with BMI ranges for adults as defined by the World Health Organisation (WHO) were used (WHO, 1995; CDC, 2009).

The body mass index (BMI) was calculated as the individual's body weight divided by the square of their height and standard categories associated with BMI ranges for adults as defined by the World Health Organisation (WHO) were used (WHO, 1995; CDC, 2009).

\section{Variables and statistical analysis}

The dependent variables were: (a) increasing BMI to overweight/obesity among those subjects with normal weight in 1994 (0: maintained weight, 1: increased BMI to overweight/obesity) and (b) change to obesity in 2002 in those subjects who were overweight in 1994 (0: maintained weight, 1: increased BMI to obesity). The independent variables included sociodemographic characteristics as collected in the 1994 baseline interview: sex (men/ women), age (continuous, and lower or higher than 45 years), marital status (single/married or living together/divorced or widowed), maximum educational level achieved (illiterate or primary studies/secondary or university studies), working status (active worker/no active worker), social class according to occupation (manual/non-manual) (Álvarez-Dardet et al, 1995), and health and lifestyle variables: self-perceived health categorized as optimal (very good or good) and suboptimal (fair, bad, very bad), alcohol consumption (no consumption: $0 \mathrm{~g} /$ day; moderate consumption: $\leq 40 \mathrm{~g} /$ day in males and $\leq 24 \mathrm{~g} /$ day in females; and risk consumption: $>40 \mathrm{~g} /$ day in males and $>24 \mathrm{~g} /$ day in females), and physical activity (sedentary/active) (Welsh Heart Health Survey, 1989; Cornelio et al. 2008), smoking behavior (smoker, former smoker, non smoker), presence of tobacco-related diseases (yes/no).

We first assessed the differences in mean BMI values using the Wilcoxon non-parametric test for two related samples (baseline and 8 years later), after checking that the data did not follow a normal distribution. We computed relative risk (RR) and 95\% confidence intervals of increasing body mass index by means of Breslow-Cox regressions, in which we considered the same follow-up period for all individuals (Breslow, 1974; Lee, 1994). This model provides the RR as the ratio of cumulative incidence rates, and we adjusted the estimates for age (continuous) and sex.

\section{Results}

Table 1 shows mean values in the BMI for the study population and for individuals that changed to a higher BMI category and annual change in BMI. In the 1008 cohort participants, the mean BMI for men and women combined increased from $25.7 \mathrm{~kg} / \mathrm{m}^{2}$ in 1994 to $26.4 \mathrm{~kg} / \mathrm{m}^{2}$ in $2002(p<0.01)$. When analysing mean BMI among people who changed from normal-weight to overweight, there was an annual average increase of $0.4 \mathrm{~kg} / \mathrm{m}^{2}$, whilst from overweight to obesity the annual average increase was $0.5 \mathrm{~kg} / \mathrm{m}^{2}$.

Table 2 shows the changes that occurred in the study population during the 1994-2002 follow-up period, in accordance with the BMI distribution categories. Out of the total sample $(n=1,008), 28.1 \%$ the subjects classified as having a normal BMI in 1994 changed to overweight in 2002. This finding was more pronounced in men (31.6\%) than in women (25.6\%). Meanwhile, the percentage of people who changed from overweight to obesity was $16.8 \%$ for the same period being higher in women $(25.8 \%)$ than in men (11.2\%). Among overweight and obese participants at baseline, $69.7 \%$ and $72.1 \%$ did not change from BMI category after 8 years. The increase in the prevalence of obesity was greater (25.7\%) than the increase in the prevalence of overweight ( $8.9 \%$ ) over the 8 years of follow-up.

Table 3 presents the cumulative incidence of overweight and obesity and its association with certain socidemographic variables after adjustment for age and sex. The cumulative incidence of overweight in men (34.0\%) was higher than in women $(26.4 \%)$, meanwhile the cumulative incidence of obesity in women was higher

\section{Table 1}

Mean values in the body mass index (BMI) for the study population and for individuals that changed to a higher BMI category. Cornellà-Spain, 1994-2002.

\begin{tabular}{|c|c|c|c|c|c|}
\hline & $n$ & $\begin{array}{l}\text { BMI in } 1994 \\
\text { Mean (SD) }\end{array}$ & $\begin{array}{l}\text { BMI in } 2002 \\
\text { Mean (SD) }\end{array}$ & $p$-value ${ }^{a}$ & $\begin{array}{l}\text { Annual change BMI } \\
\mathrm{kg} / \mathrm{m}^{2}\end{array}$ \\
\hline \multicolumn{6}{|c|}{ (1a) Body mass index (1994 and 2002) among those subjects with complete follow-up } \\
\hline Females & 508 & $25.4(4.6)$ & $26.2(4.9)$ & $p<0.001$ & 0.10 \\
\hline Males & 500 & $26.0(3.2)$ & $26.6(3.6)$ & $p<0.001$ & 0.08 \\
\hline Overall & 1008 & $25.7(4.0)$ & $26.4(4.3)$ & $p<0.001$ & 0.09 \\
\hline \multicolumn{6}{|c|}{$\begin{array}{l}\text { (1b) Body mass index among subjects with normal weight in } 1994 \text { who became } \\
\text { overweight after } 8 \text { years of follow-up }\end{array}$} \\
\hline Females & 68 & $23.2(1.3)$ & $26.5(1.2)$ & $p<0.001$ & 0.41 \\
\hline Males & 64 & $23.7(1.0)$ & $26.8(1.8)$ & $p<0.001$ & 0.39 \\
\hline Overall & 132 & $23.5(1.2)$ & $26.7(1.5)$ & $p<0.001$ & 0.40 \\
\hline \multicolumn{6}{|c|}{$\begin{array}{l}\text { (1c) Body mass index }\left(\mathrm{kg} / \mathrm{m}^{2}\right) \text { among overweight subjects in } 1994 \text { who became obese } \\
\text { after } 8 \text { years of follow-up }\end{array}$} \\
\hline Females & 40 & $27.9(1.3)$ & $32.1(2.2)$ & $p<0.001$ & 0.53 \\
\hline Males & 28 & $28.2(1.2)$ & $31.9(2.4)$ & $p<0.001$ & 0.46 \\
\hline Overall & 68 & $28.0(1.27)$ & $32.0(2.3)$ & $p<0.001$ & 0.50 \\
\hline
\end{tabular}

a Wilcoxon non-parametric test for two related samples.

(29.9\%) than in men (13.1\%). At the end of the follow-up period, we observed a statistically significant association between marital status and increasing BMI to overweight (married, $\mathrm{RR}=2.0 ; 95 \% \mathrm{CI}: 1.2-3.4$; divorced/widowed, $\mathrm{RR}=4.0 ; 95 \% \mathrm{CI}: 1.7-9.3$ ) and moderate alcohol consumption $(\mathrm{RR}=1.86 ; 95 \% \mathrm{CI}: 1.1-3.1)$. In the sex and age-adjusted obesity incidence rates, no variable was significant. In the change from

Table 2

Distribution of body mass index (BMI) categories at baseline and after 8 years of followup. Cornellà-Spain, 1994-2002.

\begin{tabular}{|c|c|c|c|c|c|c|}
\hline \multirow[t]{2}{*}{ Year 1994} & & \multicolumn{5}{|l|}{ Year 2002} \\
\hline & & Underweight & Normal & Overweight & Obesity & Total \\
\hline \multicolumn{7}{|c|}{$n=1008$ (both sexes combined) } \\
\hline \multirow[t]{2}{*}{ Underweight } & $n$ & 6 & 8 & 0 & 0 & 14 \\
\hline & $\%$ & 42.9 & 57.1 & 0 & 0 & 100 \\
\hline \multirow[t]{2}{*}{ Normal } & $n$ & 6 & 314 & 127 & 5 & 452 \\
\hline & $\%$ & 1.3 & 69.5 & 28.1 & 1.1 & 100 \\
\hline \multirow[t]{2}{*}{ Overweight } & $n$ & 2 & 57 & 279 & 68 & 406 \\
\hline & $\%$ & 0.5 & 14.0 & 68.7 & 16.8 & 100 \\
\hline \multirow[t]{2}{*}{ Obesity } & $n$ & 0 & 2 & 36 & 98 & 136 \\
\hline & $\%$ & 0 & 1.5 & 26.4 & 72.1 & 100 \\
\hline \multicolumn{2}{|l|}{$N$ total } & 14 & 381 & 442 & 171 & 1008 \\
\hline \multicolumn{7}{|c|}{$n=508$ (females) } \\
\hline \multirow[t]{2}{*}{ Underweight } & $n$ & 4 & 7 & 0 & 0 & 11 \\
\hline & $\%$ & 36.4 & 63.6 & 0 & 0 & 100 \\
\hline \multirow{2}{*}{ Normal } & $n$ & 4 & 190 & 67 & 1 & 262 \\
\hline & $\%$ & 1.5 & 72.5 & 25.6 & 0.4 & 100 \\
\hline \multirow[t]{2}{*}{ Overweight } & $n$ & 0 & 21 & 94 & 40 & 155 \\
\hline & $\%$ & 0 & 13.6 & 60.6 & 25.8 & 100 \\
\hline \multirow[t]{2}{*}{ Obesity } & $n$ & 0 & 2 & 17 & 61 & 80 \\
\hline & $\%$ & 0 & 2.5 & 21.3 & 76.2 & 100 \\
\hline \multicolumn{2}{|l|}{$N$ Total } & 8 & 220 & 178 & 102 & 508 \\
\hline \multicolumn{7}{|c|}{$n=500$ (males) } \\
\hline \multirow[t]{2}{*}{ Underweight } & $n$ & 2 & 1 & 0 & 0 & 3 \\
\hline & $\%$ & 66.7 & 33.3 & 0 & 0 & 100 \\
\hline \multirow[t]{2}{*}{ Normal } & $n$ & 2 & 124 & 60 & 4 & 190 \\
\hline & $\%$ & 1.1 & 65.2 & 31.6 & 2.1 & 100 \\
\hline \multirow[t]{2}{*}{ Overweight } & $n$ & 2 & 36 & 185 & 28 & 251 \\
\hline & $\%$ & 0.8 & 14.3 & 73.7 & 11.2 & 100 \\
\hline \multirow[t]{2}{*}{ Obesity } & $n$ & 0 & 0 & 19 & 37 & 56 \\
\hline & $\%$ & 0 & 0 & 33.9 & 66.1 & 100 \\
\hline$N$ total & & 6 & 161 & 264 & 69 & 500 \\
\hline
\end{tabular}

Underweight (BMI $<18.5 \mathrm{~kg} / \mathrm{m}^{2}$ ), normal (BMI $18.5-24.9 \mathrm{~kg} / \mathrm{m}^{2}$ ), overweight (BMI 25$\left.29.9 \mathrm{~kg} / \mathrm{m}^{2}\right)$, Obesity $\left(\mathrm{BMI} \geq 30 \mathrm{~kg} / \mathrm{m}^{2}\right)$.

Changes in the distribution of body mass index. 
Table 3

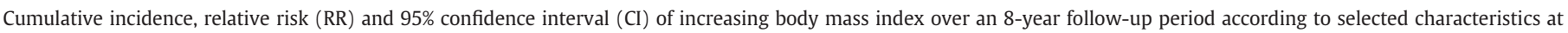
baseline.

\begin{tabular}{|c|c|c|c|c|c|c|c|}
\hline & & \multicolumn{3}{|c|}{ Normal to overweight/obesity } & \multicolumn{3}{|c|}{ Overweight to obesity } \\
\hline & & $n$ & $\begin{array}{l}\text { Cumulative } \\
\text { Incidence }\end{array}$ & $\begin{array}{l}\mathrm{RR}(95 \% \mathrm{CI}) \text { Sex } \\
\text { and age adjusted }\end{array}$ & $n$ & $\begin{array}{l}\text { Cumulative } \\
\text { Incidence }\end{array}$ & $\begin{array}{l}\mathrm{RR}(95 \% \mathrm{CI}) \text { Sex } \\
\text { and age adjusted }\end{array}$ \\
\hline \multirow[t]{2}{*}{ Sex } & Females & 68 & 26.4 & 1 & 40 & 29.9 & 1 \\
\hline & Males & 64 & 34.0 & $1.18(0.8-1.7)$ & 28 & 13.1 & $0.49(0.3-0.8)$ \\
\hline \multirow[t]{2}{*}{ Age } & $<45$ & 74 & 26.4 & 1 & 20 & 17.4 & 1 \\
\hline & $\geq 45$ & 58 & 34.9 & $1.40(0.9-2.0)$ & 48 & 20.7 & $1.11(0.7-1.9)$ \\
\hline \multirow[t]{3}{*}{ Marital status } & Single & 27 & 20.6 & 1 & 7 & 17.5 & 1 \\
\hline & Married & 94 & 32.8 & $2.00(1.2-3.4)$ & 56 & 19.7 & $0.67(0.3-1.6)$ \\
\hline & Divorced/widowed & 11 & 40.7 & $4.00(1.7-9.3)$ & 5 & 21.7 & $0.41(0.1-1.5)$ \\
\hline \multirow[t]{2}{*}{ Educational level } & $\leq$ Primary & 92 & 31.1 & 1 & 58 & 20.6 & 1 \\
\hline & Secondary + Univ. & 40 & 26.7 & $1.11(0.7-1.7)$ & 9 & 14.1 & $0.91(0.4-2.0)$ \\
\hline \multirow[t]{2}{*}{ Working status } & Active worker & 72 & 33.2 & 1 & 24 & 16.2 & 1 \\
\hline & No active worker & 60 & 26.3 & $0.81(0.6-1.2)$ & 42 & 21.3 & $1.00(0.6-1.8)$ \\
\hline \multirow[t]{2}{*}{ Social class } & Manual & 90 & 31.4 & 1 & 48 & 19.4 & 1 \\
\hline & Non-manual & 36 & 26.3 & $0.87(0.6-1.3)$ & 16 & 17.6 & $0.84(0.5-1.5)$ \\
\hline \multirow[t]{2}{*}{ Self-perceived health } & Optimal & 118 & 29.8 & 1 & 52 & 18.8 & 1 \\
\hline & Suboptimal & 14 & 28.0 & $1.03(0.6-1.8)$ & 16 & 22.9 & $1.17(0.7-2.1)$ \\
\hline \multirow[t]{3}{*}{ Alcohol consumption } & Nondrinker & 22 & 22.7 & 1 & 17 & 38.6 & 1 \\
\hline & Moderate consumption & 61 & 35.7 & $1.86(1.1-3.1)$ & 21 & 15.7 & $0.54(0.3-1.1)$ \\
\hline & Risk consumption & 10 & 38.5 & $2.11(1.0-4.7)$ & 6 & 21.4 & $0.96(0.3-2.7)$ \\
\hline \multirow[t]{2}{*}{ Physical activity } & Sedentary & 21 & 23.1 & 1 & 20 & 22.7 & 1 \\
\hline & Active & 111 & 31.4 & $1.19(0.7-1.9)$ & 46 & 18.0 & $0.67(0.4-1.2)$ \\
\hline \multirow[t]{3}{*}{ Smoking status } & Smoker & 52 & 27.2 & 1 & 14 & 21.2 & 1 \\
\hline & Former smokers & 14 & 30.4 & $0.95(0.5-1.7)$ & 14 & 21.2 & $1.09(0.5-2.3)$ \\
\hline & Non-smoker & 66 & 31.9 & $1.05(0.7-1.6)$ & 38 & 57.6 & $1.15(0.5-2.5)$ \\
\hline \multirow[t]{2}{*}{ Tobacco-related diseases ${ }^{\mathrm{a}}$} & No & 84 & 27.2 & 1 & 32 & 16.5 & 1 \\
\hline & Yes & 48 & 35.0 & $1.33(0.9-1.9)$ & 36 & 23.5 & $1.02(0.6-1.7)$ \\
\hline
\end{tabular}

Cornellà, Spain, 199-2002.

In some variables the sum does not up the total because of missing values.

a Tobacco-related diseases: heart diseases. high pressure. varicose veins. chronic bronchitis. gastroduodenal ulcer. cerebrovascular disease.

overweight to obesity analysis, women showed a greater tendency towards an increasing BMI and, when adjusted for sex and age, a statistically significant lower risk was observed for men $(R R=0.49$; 95\% CI: 0.3-0.8).

\section{Discussion}

This study examined that the cumulative incidence of obesity among overweight subjects at baseline is twice as high in women $(29.9 \%)$ than in men. In the sex- and age-adjusted incidence of obesity, a statistically significant lesser risk was only observed for men and no association appear with other socioeconomic and lifestyle variables. Of all participants, $16.8 \%$ had changed from overweight BMI in 1994 to obesity in 2002 with scarce differences by sex. Changes in the distribution of body mass index through the population (both sexes combined) showed that increasing obesity (25.7\%) was significantly higher than the increase in overweight (8.86\%).

In Cornellà's population, the BMI mean annual increase was 0.09 units over the 8-year period, at a slightly higher rate in females $\left(0.10 \mathrm{~kg} / \mathrm{m}^{2}\right)$ than in males $\left(0.08 \mathrm{~kg} / \mathrm{m}^{2}\right)$. Some cohort studies reported in the scientific literature show annual BMI increases similar to our findings, specifically, those studies carried out in England in 1993-1994 and 2002-2003 (Wardle \& Boniface, 2008) (women $0.12 \mathrm{~kg} / \mathrm{m}^{2}$ and men $0.11 \mathrm{~kg} / \mathrm{m}^{2}$ ). In Norway (Reas et al., 2007; Jacobsen et al., 2001) and Sweden as a whole (Nafziger et al., 2007), women females have presented a greater annual BMI increase of $0.16 \mathrm{~kg} / \mathrm{m}^{2}$ and $0.19 \mathrm{~kg} / \mathrm{m}^{2}$, respectively, compared with an annual BMI increase in men of $0.14 \mathrm{~kg} / \mathrm{m}^{2}$ in Norway and $0.16 \mathrm{~kg} / \mathrm{m}^{2}$ in Sweden. Meanwhile, in Western Sweden (Berg et al., 2005) (women $0.06 \mathrm{~kg} / \mathrm{m}^{2}$ and men $\left.0.09 \mathrm{~kg} / \mathrm{m}^{2}\right)$ and in the USA women $\left(0.03 \mathrm{~kg} / \mathrm{m}^{2}\right)$ showed a lower rate of increase compared to men $\left(0.05 \mathrm{~kg} / \mathrm{m}^{2}\right)$ (Parikh et al., 2007). It is remarkable that the results from England (Wardle \& Boniface, 2008) coincide with those presented in this study as regards the mean overweight BMI population $\left(25.7 \mathrm{~kg} / \mathrm{m}^{2}\right)$ in the baseline interview, whilst in Norway (Reas et al., 2007; Jacobsen et al., 2001) and Sweden (Nafziger et al., 2007; Berg et al., 2005) the population is found to be within the normal mean BMI ranges. All the studies reported that the mean BMI was greater in men than in women at the beginning of each study.

Data from the Spanish cohort of the European Prospective Investigation into Cancer and Nutrition (EPIC-Spain) showed different results on the incidence of overweight and obesity between 1992 and 1996 (Mendez et al., 2006). During the 3-year follow-up, 7.9\% of overweight women and $6.9 \%$ of overweight men became obese and, among initially normal weight subjects, $13.8 \%$ of normal weight women and $23.0 \%$ of normal weight men became overweight. The results show that annual changes in BMI were greater in subjects classified as obese than those with overweight, which is in accordance with our findings. A systematic analysis of the incidence of overweight, as used in the Framingham study (Parikh et al., 2007), showed a combined annual overweight incidence rate of $4.2 \%$, higher in men and coincides with our results. Meanwhile, the Framingham study reports a lower annual obesity incidence rate than our research at $1.8 \%$, which is extremely similar in both women (1.8\%) and men (1.9\%). The gradual increase in the incidence of overweight and obesity over time indicates that the greater prevalence rates are not just a recent trend (Parikh et al., 2007). Similar results reporting a higher annual overweight incidence rate $(2.6 \%)$ than obesity $(1.1 \%)$ were found in an African population (Nemesure et al, 2008) rates among women almost twice that of men. Direct comparisons with other studies as regards annual incidences should be interpreted with caution and have been used here strictly for comparative purposes.

The results of this study as well as those published in previous comparative studies reveal that obesity currently affects women and men to the same extent. However, our study specifically indicates that the incidence of overweight is much higher in men than in women, 
whilst obesity is more frequent amongst women than men. According to the 2006 Spanish National Health Interview Survey, prevalence of obesity in Spanish adults is continuing to rise at approximately the same rate for both females (15.2\%) and males (15.6\%) (Ministry of Health and Consumer Affairs of Spain, 2006).

Some of the interesting socio-economic and lifestyle patterns presented in the results of this study are in line with those from other longitudinal studies whilst others differ. The ARIC cohort study showed that the increases in BMI over time were not clearly related to socio-economic factors (Mujahid et al., 2005). Similar information showed that inequality in adiposity in England is not related to demographic characteristics such as social class or sex (Wardle \& Boniface, 2008). In a Norwegian cohort (Reas et al., 2007), all levels of income and education demonstrated weight gain between 1990 and 2001, with no differential associations. No significant findings existed between the socio-economic indicators and changes in BMI over time. Some have argued that social and economic gaps in BMI distribution may ultimately be narrow, owing to blanket exposure to an increasingly obesogenic environment (Reas et al., 2007). However, obesity is characterised by a considerable social inequality, as it is most prevalent among groups with a lower level of education and from manual social classes (Heitmann, 2000). When interpreting such differences, Lyratzopoulos et al (2005) concluded that the methodological differences in a wider range of factors, including the study population, age of participants, length of follow-up, BMI measurement, measurement of socio-economic status and the analytical approaches used should be taken into consideration.

These results suggest the need to develop strategies in order to reverse today's obesity trends in Mediterranean countries. The fact that the annual increase in overweight and obesity rates affects both men and women indicates that not only diet and physical exercise are the main contributors to the current epidemic. Other environmental factors, in particular those related to policies, economics and advertising also have an impact on the choice of less healthy options by individuals (Millstone \& Lobstein, 2007). In fact, studies on the relationship between dietary patterns in Mediterranean countries and BMI conclude that adherence to a Mediterranean diet was essentially unrelated to BMI (Trichopoulou et al, 2005), and Mediterranean diet adherence was not associated with overweight incidence in initially normal-weight subjects (Mendez et al., 2006). Therefore, overweight and obesity are common problems in Mediterranean countries, although they are likely to be related to limited physical activity in conjunction with excessive positive energy balance brought about by the westernization of the Mediterranean diet (Sanchez-Villegas et al., 2006; Trichopoulou et al, 2005; Mendez et al., 2006).

Due to the small size of the sample it has not been possible to stratify results into the different potentially interesting population subgroups such as, for example, age or social class groups. Unfortunately the questionnaire used did not incorporate dietary items in order to assess the dietary pattern, the calorie intake or specific food consumption that would have been useful in the overall analysis of BMI changes. Finally, some selection bias due to attrition is also possible in cohort studies. In our cohort, almost two-thirds of the subjects who did not respond to the follow-up interview had died or moved to another town, and attrition due to death was more frequent among sedentary people, that in turn, can be related to BMI (Garcia et al., 2005a). As also shown previously (Garcia et al., 2005a), attrition was non-random but there was no serious bias in estimates of change and in determinants of change due to attrition.

\section{Conclusions}

The increase in the incidence of obesity in a Mediterranean region coincides with the increase reported in other regions, which suggests a similar evolution in the obesity epidemic regardless of Mediterranean dietary patterns in our population.

\section{Conflict of Interest}

The authors declare have no conflict of interest.

\section{Acknowledgments}

This study was partially funded by the Spanish Ministry of Health (Fondo de Investigación Sanitaria, PI02/0261), and the Carlos III Health Institute-Research Network in Epidemiology and Public Health, RCESP C03/09, CIBERESP CB06/02/00328, and the Research Network in Cancer, (RTICC C03/10, RD06/0020/0089), and by the Generalitat of Cataluya (SGR 200500646).

\section{Appendix A. Supplementary data}

Supplementary data associated with this article can be found, in the online version, at doi:10.1016/j.ypmed.2009.11.008.

\section{References}

Álvarez-Dardet, C., Alonso, J., Domingo, A., Regidor, E., coord., 1995. La medición de la clase social en ciencias de la salud. Barcelona: SG-Editores, Sociedad Española de Epidemiología.

Breslow, N., 1974. Covariance analysis of censored survival data. Biometrics 30, 89-99. Berg, C., Rosengern, A., Aires, N., Lappas, G., Torén, K., Lissner, L., 2005. Trends in overweight and obesity from 1985 to 2002 in Göteborg, West Sweden. Int. J. Obes. 29, 916-924.

Cornelio, C.I., García, M., Schiaffino, A., Borràs, J.M., Nieto, F.J., Fernández, E., 2008. Changes in leisure time and occupational physical activity over 8 years. The Cornella Health Interview Survey Follow-Up Study. J. Epidemiol. Commun. Health 62, 239-244.

Flegal, K.M., Carroll, M.D., Ogden, C.L., Johnson, C.L., 2002. Prevalence and trends in obesity among US adults, 1999-2000. J. Am. Med. Assoc. 288, 1723-1727.

Garcia, M., Fernandez, E., Schiaffino, A., Borrell, C., Marti, M., Borras, J.M., 2005a. Attrition in a Population-Based Cohort eight years after baseline interview: The Cornella Health Interview Survey Follow-up Study (CHIS.FU). Ann. Epidemiol. 15, 98-104.

Garcia, M., Fernandez, E., Schiaffino, A., Peris, M., Borras, J.M., Nieto, F.J., 2005b. Phonetracking in a follow-up study (Spain). Soz. Praventivmed. 50, 63-66.

Garcia, M., Schiaffino, A., Fernandez, E., et al., 2003. The Cornellà Health Interview Survey Follow-up (CHIS.FU) Study: design, methods, and response rate. BMC Public Health 3, 12.

Haftenberger, M., Lahmann, P.H., Panico, S., et al., 2002. Overweight, obesity and fat distribution in 50- to 64-year-old participants in the European Prospective Investigation into Cancer and Nutrition (EPIC). Public Health Nutr. 5, 1147-1162.

Heitmann, B.L., 2000. Ten-year trends in overweight and obesity among Danish men and women aged 30-60 years. Int. J. Obes. 24, 1347-1362.

International Obesity Task Force (IOTF), 2002. Obesity in Europe. The case for action. Available at: http://www.iotf.org/media/euobesity.pdf. Accessed April, 2008.

Jacobsen, B.K., Njø, I., Thune, I., Wilsgaard, T., Løchen, M.L., Schimer, H., 2001. Increase in weight in all birth cohorts in a general population: The Tromsø study, 1974-1994. Arch. Intern. Med. 161, 466-472.

Lyratzopoulos, G., McElduff, P., Heller, R.F., Hanily, M., Lewis, P., 2005. Mid-term body index increase among obese and non-obese individuals in middle life and deprivation status: a cohort study. BMC Public Health 5, 1-11.

Mendez, M.A., Popkin, B.M., Jakszyn, P., et al., 2006. Adherence to a Mediterranean diet is associated with reduced 3-year incidence of obesity. J. Nutr. 136, 2934-2938.

Millstone, E., Lobstein, T., 2007. The PorGrow project: overall cross-national results, comparisons and implications. Obes. Rev. 8, 29-36.

Ministerio de Sanidad y Consumo de España, 2006. Encuesta Nacional de Salud de España 2006. A Report from Ministry of Health and Consumer Affairs of Spain Available at: http://www.msc.es/estadEstudios/estadisticas/encuestaNacional/ encuesta2006.htm. Accessed Feb, 2009.

Mujahid, M.S., Diez-Roux, A.V., Borell, L.N., Nieto, J., 2005. Cross-sectional and longitudinal associations of BMI with socio-economic characteristics. Obes. Res. 13, 1412-1421.

Nafziger, A.N., Lindvall, K., Norberg, M., et al., 2007. Who is maintaining weight in a middle-aged population in Sweden? A longitudinal analysis over 10 years. BMC Public Health 7, 1-10.

Nemesure, B., WuS, Y., Hennis, A., Leske, M.C., 2008. Nine-year incidence of obesity and overweight in an African-origin population. Int. J. Obes. (Lond.) 32, 329-335.

Parikh, N.I., Pencina, M.J., Wang, T.J., et al., 2007. Increasing trends in incidence of overweight and obesity over 5 decades. Am. J. Med. 120, 242-250.

Reas, D.L., Nygard, J.F., Svensson, E., Sorensen, T., Sandanger, I., 2007. Changes in body mass index by age, gender, and socio-economic status among a cohort of Norwegian men and women (1990-2001). BMC Public Health 7, 269. Available at: http://www.biomedcentral.com/content/pdf/1471-2458-7-269.pdf. Accessed Sep, 2007.

Sanchez-Villegas, A., Bes-Rastrollo, M., Martinez-Gonzalez, M.A., Serra-Majem, L., 2006 Adherence to a Mediterranean dietary pattern and weight gain in a follow-up study: the SUN cohort. Int. J. Obes. (Lond) 30, 350-358.

Sanz-de-Galdeano, A., 2005. The Obesity Epidemic in Europe. IZA Discussion Paper No. 1814. Available at: http://ssrn.com/abstract $=840745$. Accessed Jun, 2008. 
Trichopoulou, A., Naska, A., Orfanos, P., Trichopoulos, D., 2005. Mediterranean diet in relation to body mass index and waist-to-hip ratio: the Greek European Prospective Investigation into Cancer and Nutrition Study. Am. J. Clin. Nutr. 82, 935-940.

Vasan, R.S., Pencina, M.J., Cobain, M., Freiberg, M.S., D’Agostino, R.B., 2005. Estimated risks for developing obesity in the Framingham Heart Study. Ann. Intern. Med. 143, 473-480.

Wardle, J., Boniface, D., 2008. Changes in the distributions of body mass index and waist circumference in English adults, 1993/1994 to 2002/2003. Int. J. Obes. 32, 527-532.
Welsh Heart Health Survey, 1989. Protocol and questionnaire: Health Promotion Authority for Wales. Technical report No. 2, Wales.

Willett, W.C., Colditz, G.A., 1998. Approaches for conducting large cohort studies. Epidemiol. Rev. 20, 91-99.

Williamson, D.F., Kahn, H.S., Byers, T., 1991. The 10-y incidence of obesity and major weight gain in black and white US women aged 30-55 y. Am. J. Clin. Nutr. 53, 1515S-1518S.

World Health Organization(WHO), 1995. Physical status: The use and interpretation of anthropometry. Report of a WHO Expert Committee. WHO Technical Report Series 854 , Geneva. 